Supplement of Biogeosciences, 17, 1897-1909, 2020

https://doi.org/10.5194/bg-17-1897-2020-supplement

(c) Author(s) 2020. This work is distributed under

the Creative Commons Attribution 4.0 License.

(c) (i)

Supplement of

\title{
From canals to the coast: dissolved organic matter and trace metal composition in rivers draining degraded tropical peatlands in Indonesia
}

Laure Gandois et al.

Correspondence to: Alison M. Hoyt (ahoyt@bgc-jena.mpg.de)

The copyright of individual parts of the supplement might differ from the CC BY 4.0 License. 


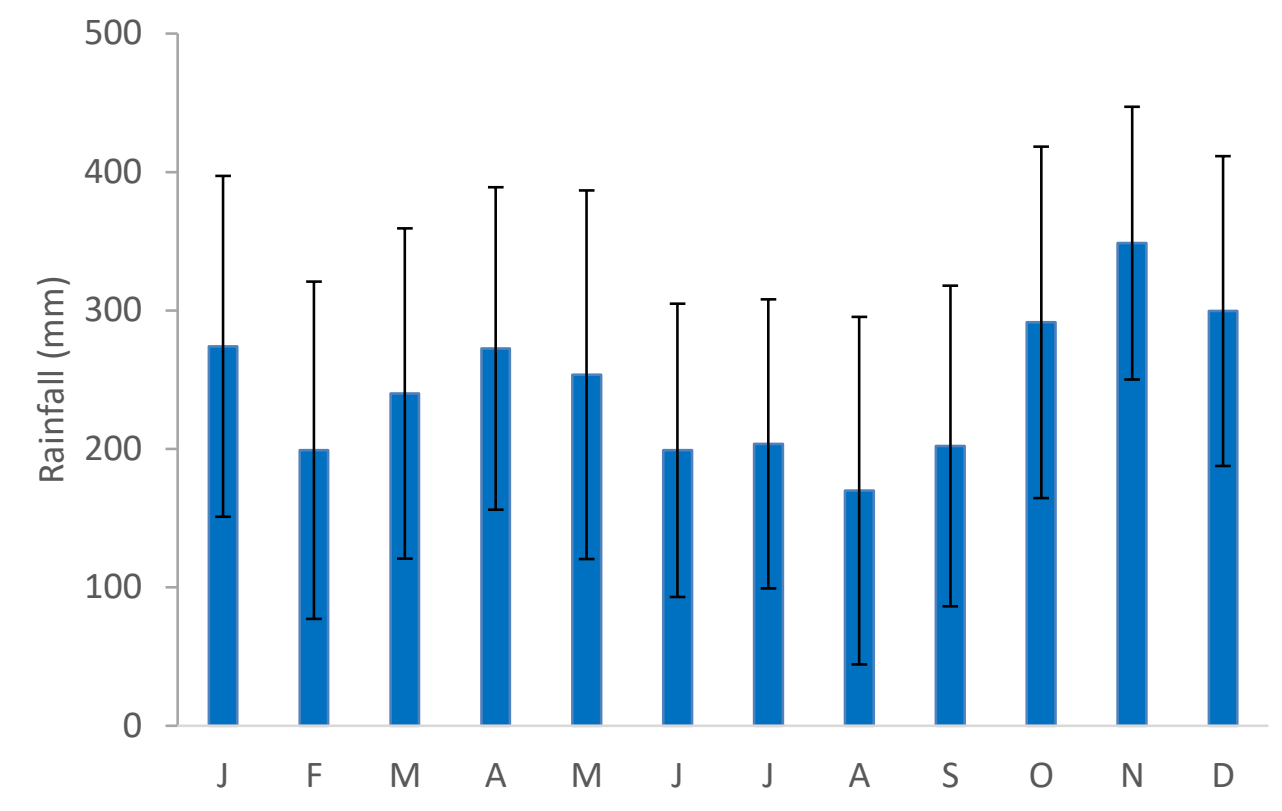

Figure S1: Mean and standard deviation of monthly rainfall amount in Pontianak (1985-2017 data). The sampling campaigns were conducted in January (end of wetter period) and June (drier period). 

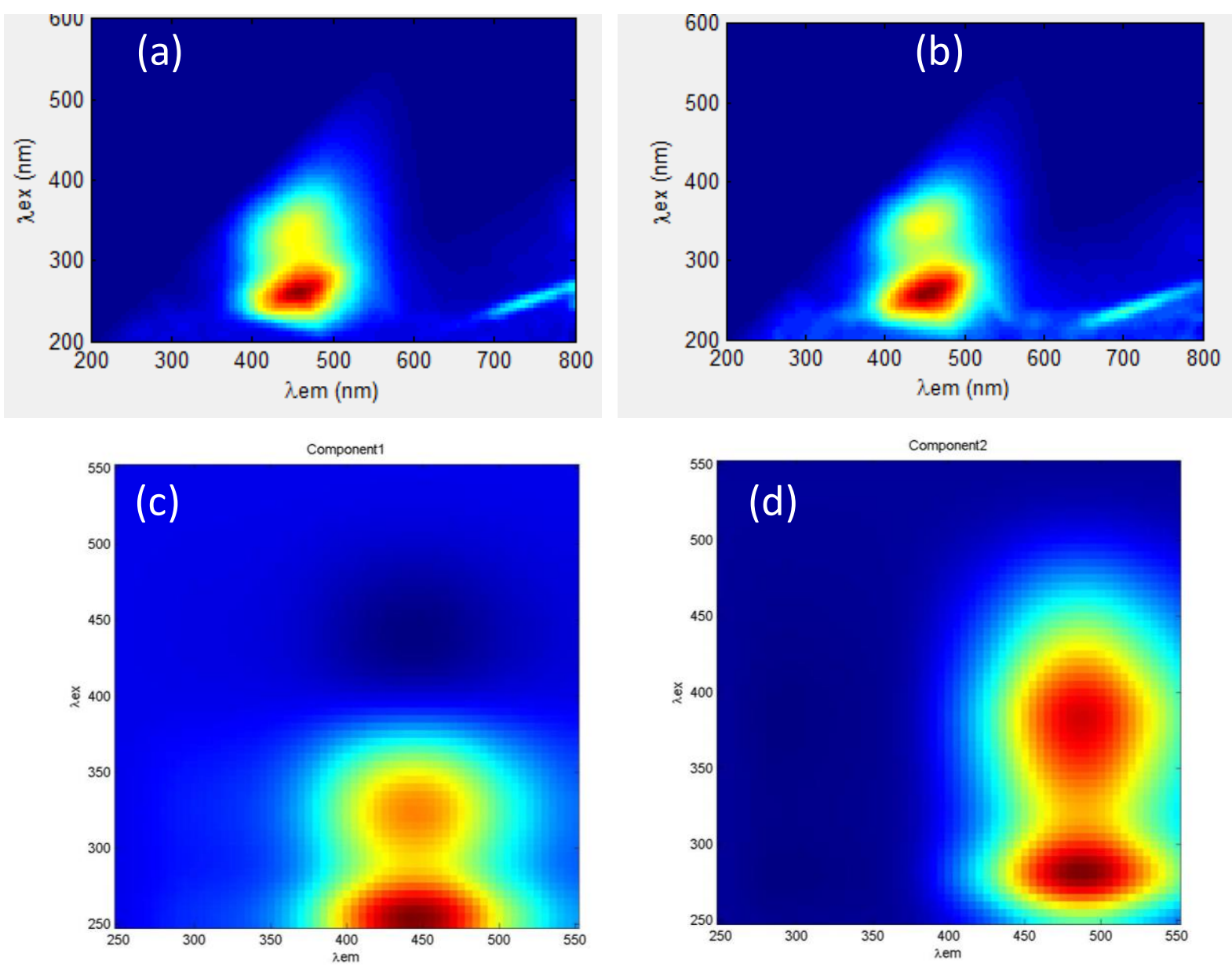

37

1

Figure S2: Typical EEMS of (a) black river and (b) white river. Main fluorophores revealed by the PARAFAC (c) $\mathrm{C} 1$ and (d) C2.

2

3




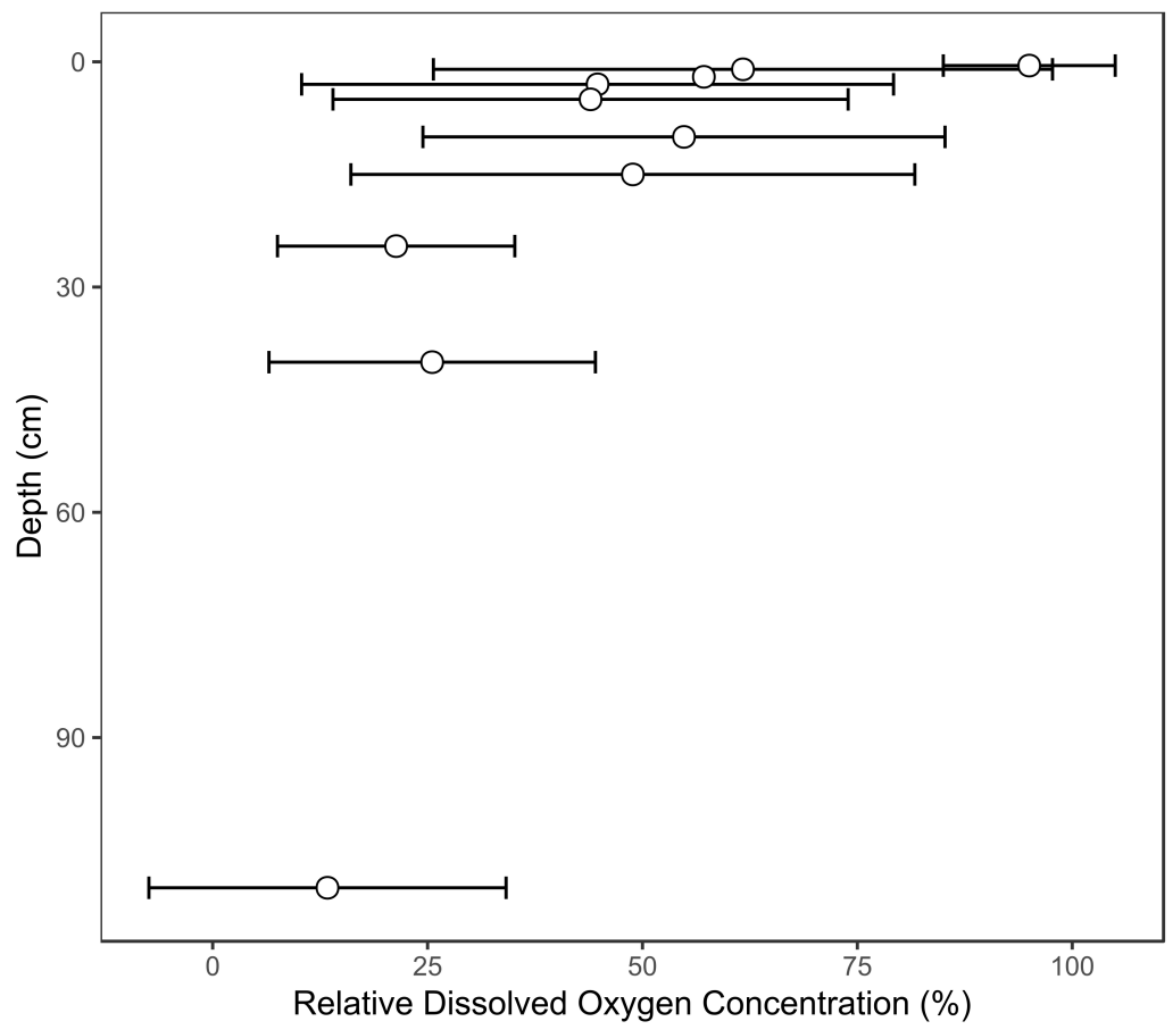

Figure S3. Relative changes in dissolved oxygen concentrations with depth in the black river. Spatial replicates of depth profiles were measured at near the river bank, $15 \mathrm{~m}$ from the edge of the river bank, and in the center of the river. Mean and standard deviations are shown. Depth profiles at all locations show a sharp decrease in dissolved oxygen with depth, indicating oxygen is consumed during the microbial processing of DOM, and likely limits decomposition rates. 